Proceedings of the 2000 Winter Simulation Conference

J. A. Joines, R. R. Barton, K. Kang, and P. A. Fishwick, eds.

\title{
GROUPWARE AND THE SIMULATION CONSULTANT
}

\author{
Simon J.E. Taylor \\ Centre for Applied Simulation Modelling \\ Department of Information Systems and Computing \\ Brunel University \\ Uxbridge, Middx, U.K.
}

\begin{abstract}
This paper recognises that good communication and interaction are key factors to the success of a simulation project and suggests that groupware technology can increase the chances of success. To underline this, the paper reviews the process of simulation to illustrate the amount of communication and interaction that must take place during a simulation project. The paper then discusses computer supported cooperative work and groupware, a research field and information technology that has successfully supported communication and interaction in other industries. To illustrate how groupware may by used by the simulation consultant, net-conferencing, exemplified by Microsoft's NetMeeting, is presented. The paper ends with some observations on the future of these applications in simulation modelling.
\end{abstract}

\section{INTRODUCTION}

Simulation modelling has been used in decision support systems to analyse aspects of organisational processes since the 1960's (Law and Kelton 1999, Pidd 1998, Robinson 1994). Robinson and Pidd (1998) study some factors that play a key role in the success of a simulation project. After interviewing providers of simulation expertise (simulation consultants) and their customers they observed that three common factors related to success were "there will be regular communication between the provider and customer," "regular meetings will be held between the customer and the provider," and "the project will be a team effort." They categorise this as Communication and Interaction (frequency, clarity and appropriateness of communication and interaction with those involved in the simulation project). One may therefore take the possibly intuitive view that a successful simulation project depends on frequent meetings between customers and providers to develop valid conceptual and computer models of an organisational process (production line, business process, scheduling system, etc.), to experiment with that model, to report on the findings of experimentation, and to make decisions based on such findings (improve the efficiency of a production process by adding/reducing resources, etc.)

In other areas of industry, where groups of people come together to take part in a common task, this has been successfully studied in the guise of Computer Supported Cooperative Work (CSCW). One of the major innovations in information technology that has resulted from this field is groupware, applications that facilitate group working. Today these applications range from pervasive electronic mail to general purpose enterprise client-server systems composed of integrated multimedia document management (Orfali et al. 1996, Poltrock and Grudin 1998). The market leaders in this field are Office/Exchange (Microsoft), Lotus Notes/Domino (IBM), and Groupwise (Novell) (News.com 1999). Implementing these systems is often expensive, with consultancy being responsible for over two thirds of the costs (Field 1996) but the adoption of groupware is usually justified by cost saving and a need to use contemporary systems. It is estimated that the groupware document management and workflow software market will represent a market of over $\$ 7$ billion by 2003 (Dataquest 1999). However, within this context there is little evidence that the benefits of groupware have been taken up by the simulation community. This is possibly due to critical mass and a lack of general knowledge about the field (as simulation consultants tend to spend their time in the task of simulation rather than the testing of new software applications). This paper attempts to make a step down the path towards the introduction of groupware in the simulation community by offering an instructive example. The paper is structured as followed. Section 2 reviews some of the basic issues in the process of simulation. Section 3 reviews computer supported cooperative work and groupware. Section 4 presents an example of groupware that may be used by the simulation consultant. Section 5 closes the paper with some general observations of the role of groupware in simulation modelling. 


\section{SIMULATION MODELLING}

Let us consider simulation modelling and part of the role that the simulation consultant plays. The process of simulation, or a simulation project, can be described in the following manner (more detailed discussions can be found in Law and Kelton (1999), Macredie et al. (1999), Pidd (1998) and Robinson (1994)). A simple reference model of a simulation project can be seen in Figure 1. A simulation project is usually initiated as result of a need to analyse a real world problem with a view to decision making (planning a new factory, studying various strategies for improving the efficiency of a manufacturing system, studying the implications of different evacuation strategies during an emergency, etc.) or to train staff in decision making in systems (military strategy, crowd control, air traffic control, manufacturing system, etc.) that cannot be studied due to cost or danger. The project usually begins by defining the problem (or training scenario) in as much detail as possible and identifying personnel to perform the study (experts in simulation and stakeholders in the system under analysis). The next step is to form a conceptual model of the physical system in which the problem exists. Diagrammatic techniques are typically used (activity cycle diagrams, event graphs; flow charts, block diagrams, etc.). Consideration must also be given to how time advances in the system (time stepped or by next event), to whether or not system activities take deterministic or stochastic time, and to how the system changes state (discretely, continuously, or both). Once there is agreement by the involved parties that the conceptual model is an adequate representation of the physical system, it is translated into a computer model, which is then tested (verified) to determine if it conforms to the computer model. If the purpose of the simulation project is to make decisions concerning a particular problem, the computer model is then combined with experimental data to attempt to discover more about the problem under investigation. Validation is carried out at all stages of the simulation project to ensure that the various models used do not deviate from the physical system being studied. Statistical analysis of experimental results can either result in recommendations as to how to solve the real world problem, or in further refinement of the problem (as more is discovered about the real world system). If the aim of the simulation project is training, experimental data is again combined with the computer simulation. The difference is that, for training, the data is not used to solve a problem but to highlight important issues that might arise in the real world system. One underlying theme in simulation is the interaction between consultant and clients. In virtually ever step of a simulation project there must be close and effective communication. Without this many errors may enter the project (imagine attempting validation without interaction with the client group). Frequent meetings of simulationists and clients (trainees) can lead to extended project times and high cost due to, for example, difficulties in scheduling and the need to travel over long distances.

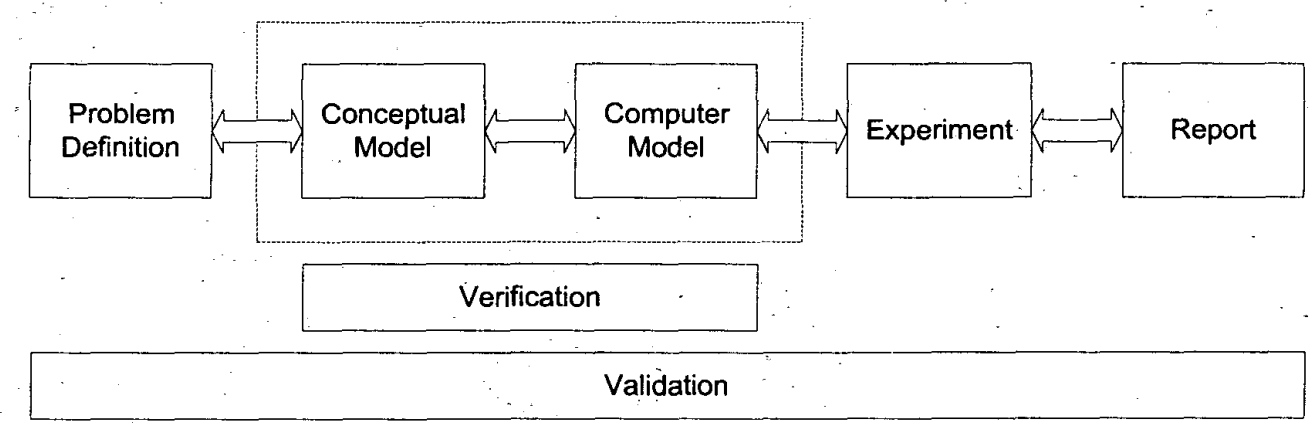

Figure 1: Simulation Modelling Process

The next section introduces $\mathrm{CSCW}$ and groupware, and gives some examples of the type of groupware applications that exist. This is followed by a discussion of one type of groupware application called net conferencing and how this may support the simulation consultant.

\section{COMPUTER SUPPORTED COOPERATIVE WORK AND GROUPWARE}

Computer Supported Cooperative Work (CSCW) is a multidisciplinary field that appeared in the early 1980's as a response to the failure of Information Technology to properly support the needs of people working in groups and organisations (Grudin 1994). It studies the development and use of computer-based methods to support work that is shared amongst individuals who may not be co-located. The field gave rise to groupware, "computer-based systems that support groups of people engaged in a common task (or goal) and that provide an interface to a shared environment (Ellis et al. 1991)" or "... software that supports the creation, flow, and tracking of non-structured information in direct support of 
collaborative group activity (Orfali et al. 1996)." There are many aspects to $\mathrm{CSCW}$ ranging from the technological (computer support) to the sociological (cooperative work). Some consider $\mathrm{CSCW}$ as focusing on the sociological aspects of IT support for group working, while others argue that groupware stresses the technological aspects of the same (Grudin 1994). As evidenced by papers in the major CSCW conferences (CSCW, ECSCW, and CHI) the balance between sociological and technological research appears to have shifted in favour of technology in the early-1990's as groupware applications began to achieve market penetration (e.g., Lotus Notes). Most of the primary foundational work is dated prior to this time (Whitaker 1996). See Baecker (1993), Grief (1988) and Johansen (1988) for major examples of this work.

The Internet, the WWW, desktop computing, office information systems, and local area networks have made possible many groupware applications. Email, is often cited as an example of successful groupware as it allows the exchange of electronic documents and promotes information flow and coordination (Sproull and Kiesler 1991). Similar points can be made about other group communication facilitation technologies such as the various forms of computer-, tele-, video-, and net-conferencing (Grudin and Palen 1995) (in this paper these are collectively referred to as X-conferencing). Information can also be shared using task-specific common media, or whiteboard variants (Ellis et al. (1991) and Whitaker (1996) cite many of these). Groupware taxonomies have been suggested for the classification of applications and products (Johansen 1991, Grudin and Poltrock 1994, 1997 and Ellis et al. 1991). Figure 2 shows a time and space taxonomy suggested by Grudin and Poltrock (1994, 1997). This indicates possible groupware applications that are useful for tasks involving different types of meetings. Generally speaking, think of a situation at work. Many of us are, for example, used to meeting clients at the same time and in the same place. In this instance meeting facilitation technologies are useful. One company reserves a room in which the walls are whiteboards. In order to discuss the development of a business process, stakeholders are encouraged to draw their perception of their own processes. As the meeting continues, the stakeholders swap position and modify any processes they disagree with. The purpose of the meeting is discover the overall perceptions (and misperceptions) of those involved in the overall business process. This is also appropriate for meetings that take place between parties who meet at different but predictable times in the same place (work shifts) and for those who meet at different but unpredictable times in the same place (drop in team rooms) and may be replaced by a computer-based whiteboard. Alternatively, for example, in those situations where we wish to collaborate with others where we do not know where they will be, but can predict to a certain extent (i.e. by email address), we can use email to conduct business. The framework is useful in that it offers different ideas as to when a particular technology may be used. This is especially true as the simulation consultant faces many working situations when some or all of these situations may occur.

Grudin and Poltrock also offer a useful framework that considers groupware from the basic supporting themes of collaboration. These include technologies that support communication, those that support information sharing, and those that support coordination. Communication technologies include electronic mail (a technology that should be familiar to most), real time X-conferencing (an example of this is presented in the next section), and multicast audio and video (used to support, for example, internet-based concerts and presentations). Information sharing technologies can be split into shared information spaces that allow synchronous or asynchronous access. The major representative of synchronous shared information spaces is the whiteboard (see next section for an example). Asynchronous shared information spaces include computer bulletin boards and threaded discussion groups (netnews, etc.), document management systems that provide for the creation and reuse of documents as well as the control of access, concurrency, and versioning. Finally, coordination technologies include calendars and schedulers and workflow management systems such as Lotus Notes and SAP.

It can be argued that many of these technologies are potentially useful to the simulation consultant. However, due to space limitations, one major example will be presented in the next section as this is a useful vehicle to demonstrate several groupware applications.

\begin{tabular}{|c|c|c|c|c|}
\hline & \multicolumn{3}{|c|}{ Time } \\
\hline & & Same & $\begin{array}{l}\text { Different but } \\
\text { predictable }\end{array}$ & $\begin{array}{l}\text { Different but } \\
\text { unpredictable }\end{array}$ \\
\hline \multirow{3}{*}{ Place } & Same & Meeting facilitation & Work shifts & Team rooms \\
\hline & $\begin{array}{l}\text { Different but } \\
\text { predictable }\end{array}$ & $\mathrm{X}$-conferencing & Electronic mail & $\begin{array}{l}\text { Collaborative } \\
\text { writing }\end{array}$ \\
\hline & $\begin{array}{r}\text { Different but } \\
\text { unpredictable }\end{array}$ & $\begin{array}{l}\text { Interactive } \\
\text { multicast seminars }\end{array}$ & $\begin{array}{l}\text { Computer bulletin } \\
\text { boards }\end{array}$ & Workflow \\
\hline
\end{tabular}

Figure 2: 3x3 Map of Groupware Options (Grudin and Poltrock 1997) 


\section{AN EXAMPLE: NET-CONFERENCING AND NETMEETING}

Net-conferencing is a same time/different but predicable place groupware application. It effectively performs the collaborative function of conferencing two or more parties working together on a particular task via the internet. One of the best examples of this technology is Microsoft's NetMeeting. The product is reported (principally in Microsoft's press) as being used for applications such as remote training, collaborative design, augmenting existing software applications, virtual team support, accessibility, user support and many other situations where the emphasis is on reducing travel costs and saving time. It provides net-conferencing with other forms of groupware in one integrated package. These are text chat, whiteboard, file transfer, and application sharing. The package does not support (at the time of writing) multi-point audio and video. This is not too limiting as (arguably) the ability to see another's image is of limited utility, and multi-point audio can be achieved via a conferencing call using a normal telephone system. NetMeeting works acceptably on a laptop connected to the internet via a normal modem (faster communications are preferable for ease of use).

NetMeeting is fairly simple to set up and is guided via a wizard. Once running, one user must "host" the meeting. This is performed by selecting one of many directory ILS servers that support NetMeeting (such as those provided by Microsoft; some companies have their own within a intranet). If a public directory server is used, to prevent unwelcome attention, it is imperative that the host registers him or herself with the option "Do not list my name in the directory" checked. If not, the host's name will appear with all other users listed on the directory server making it possible for anyone to connected to the host. Private meetings are usually conducted by passing the host's name to all participants privately (via email for example). Connecting to a host is a simple matter of typing in the host's address and "placing a call."

Figure 3 shows an example screen shot of NetMeeting. The front end of the package is in the top left hand corner of the screen. It consists of a title bar displaying the status of the call (in this example there are two people in the call - this is shown by "1 Connection"). The address of the host is shown below the option bar and below that is the video image of the host (NetMeeting can only connect two participants by video). To the right of this are three icons that place a call, hang up a call, and list the participants of the directory sever. Below the video window are three buttons that alternatively control the video image, place a local video image within the remote video image window; and control the audio settings. Below that are the names of the meeting participants. Finally, the four buttons at the bottom of the NetMeeting window invoke the four integrated groupware applications. These are (from left to right) application sharing, text chat, whiteboard, and file transfer. The larger part of the screen shot is taken by a simulation application (in this case the simulation program is Visual Thinking International's Simul8 with a simple job shop taken from the packages model library).

In figure 4 the NetMeeting window has been minimised to clear space. The figure shows the text chat and whiteboard applications. The text chat is useful for two reasons. If there is no realistic means of connecting participants together via a conference call, then a useful alternative is to connect via the text chat. This can be troublesome as, particularly for longer exchanges, to use the text chat a participant must type in his or her contribution to the chat session in the message box and then -hit return to send it to one or more participants (the application provides the functionality for "side conversations"). Users can become impatient for those of us who are slow typists (sometimes the impression is given that the text chat session has crashed). On the plus side, text chat presents the opportunity for the development of many-way documentation and agreement, something that is perhaps difficult to attain via -an exchange of emails (consider the problems of decision making with many users by email!) Text chat also provides security encryption and the ability to save a chat session as a permanent record of the meeting. -The whiteboard application is useful as a multi-user "flip chart"; users connected to the NetMeeting session can access the whiteboard as and how they wish. The rather fictitious example is a conversation between consultant and client where the consultant is attempting to get a feel for how jobs arrive in the client's factory. The whiteboard (similar in look and feel to Microsoft's Paint) shows the client's first attempt to describe how the rate of job arrival varies over time. One could see the remote conversation continuing by the consultant showing the user how the distribution could be translated into a valid representation in the model.

Another application is File Transfer. This appears in a similar form to text chat; a menu of participants lists allows the user to choose to transfer a file to another single participant or to the entire complement of participants. The ability to transfer files between users is similar to attaching a file to an email. The integration of this application into NetMeeting is useful as it reduces the number of different applications that a user must select during a conferencing session. The ability to transfer files to all participants in the meeting is also useful as one can ensure that at the end of a meeting all participants can receive a copy of the same file (possibly reducing another source of confusion and error). In terms of simulation, a consultant can make sure that all clients have the same copy of the data, model, etc. if necessary.

The final, and possibly most powerful feature of this package is the Application Sharing feature. This allows a participant in a NetMeeting session to share any application running on his or her computer. For example, a 
simulation package can be "shared" by selecting Application Sharing and selecting the simulation package from a list of running applications that NetMeeting can find on that participant's computer. Once the package has been shared, all participants receive an image of the package as if it were running locally on their computer (the simulation package show in figures 3 and 4 is actually running on the computer of the other participant in the conferencing session). Each participant can see the shared package and the results of any manipulation performed by the owner of the package. For example, the owner may communicate to the other participants (by text chat for example) that $\mathrm{s} /$ he is going to run the model to demonstrate how a part of the model works to the other participants. The owner runs the model as normal and the other participants will see the model animation as if the package were running on their own computer (with the caveat of communication speed). If one of the participants wanted to point out a model feature, or indeed stop the model and change some aspect of the model, the participant could request control from the owner. If control is granted, then all participants will see the mouse arrow annotated with the ID of the participant. The participant is then in direct control of the package running on the remote machine of the owner.

\section{CONCLUSIONS}

Returning to Robinson and Pidd's observation of the importance of communication and interaction between the consultant and the client(s). Intuitively it seems that groupware such as net-conferencing can greatly benefit the simulation consultant by supporting communication and interaction over distance. It does not represent a panacea in terms of the success of communication and interaction, but the ability (at least for net-conferencing) to reduce the need for face-to-face meetings and increase the frequency of interaction does appear to present the opportunity for cost-savings and increased information exchange.

To determine how real this is, a study is being carried out by the author of this paper. The net-conferencing application has been demonstrated by the author to simulation modellers acting within various companies and at the July 2000 meeting of the UK Operational Research Society Simulation Study Group. The purpose of the demonstrations is to derive a collaborative methodology (or at least best practice recommendations) based on the use of net conferencing in simulation modelling. The results of this survey will be available at the time of the conference. This work forms part of a wider research programme investigating the use of groupware in simulation modelling and is in turn part of the GROUPSIM research programme (supported by EPSRC grant GR/N35304).

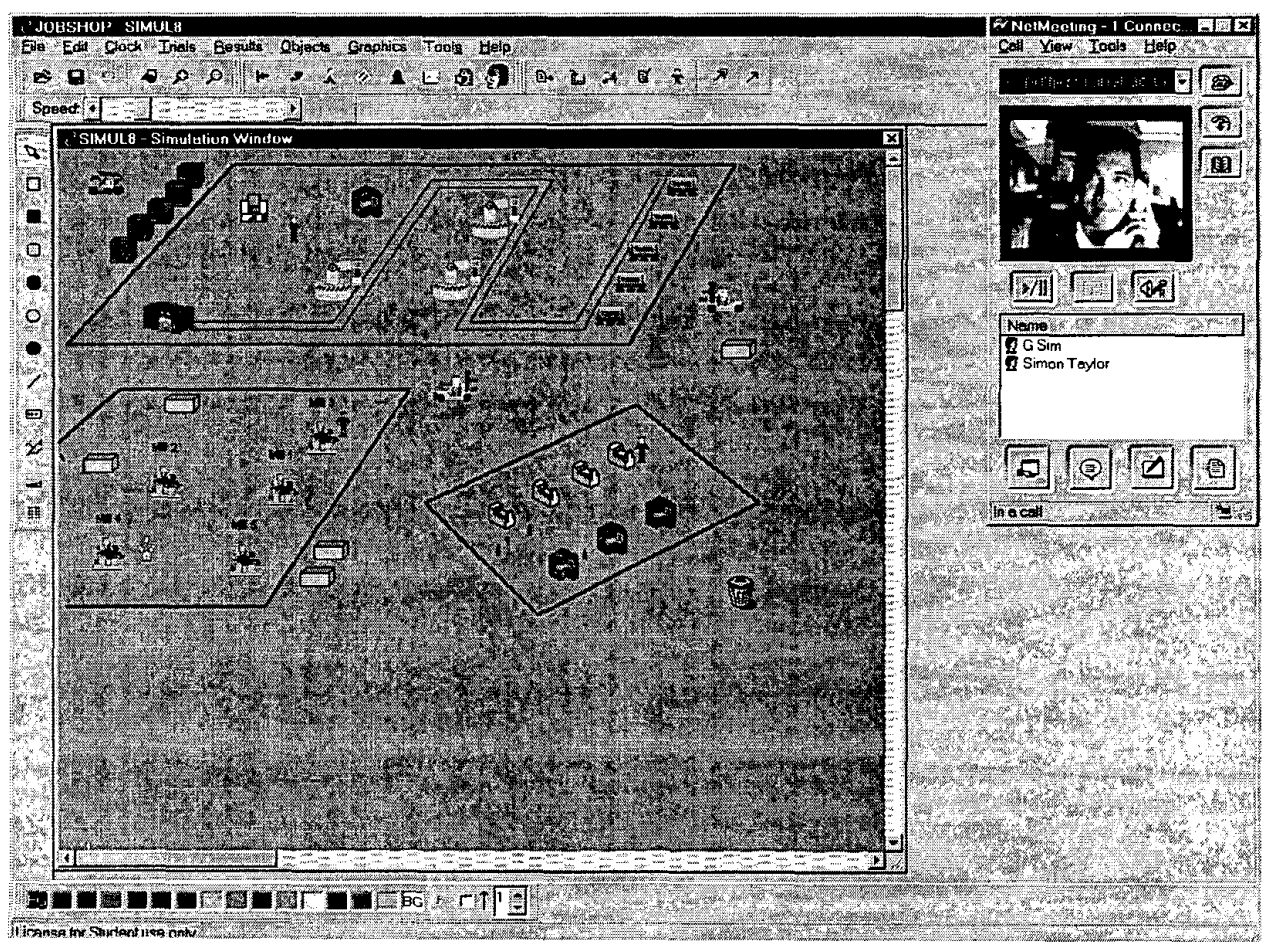

Figure 3: NetMeeting and Simulation Software 
Taylor

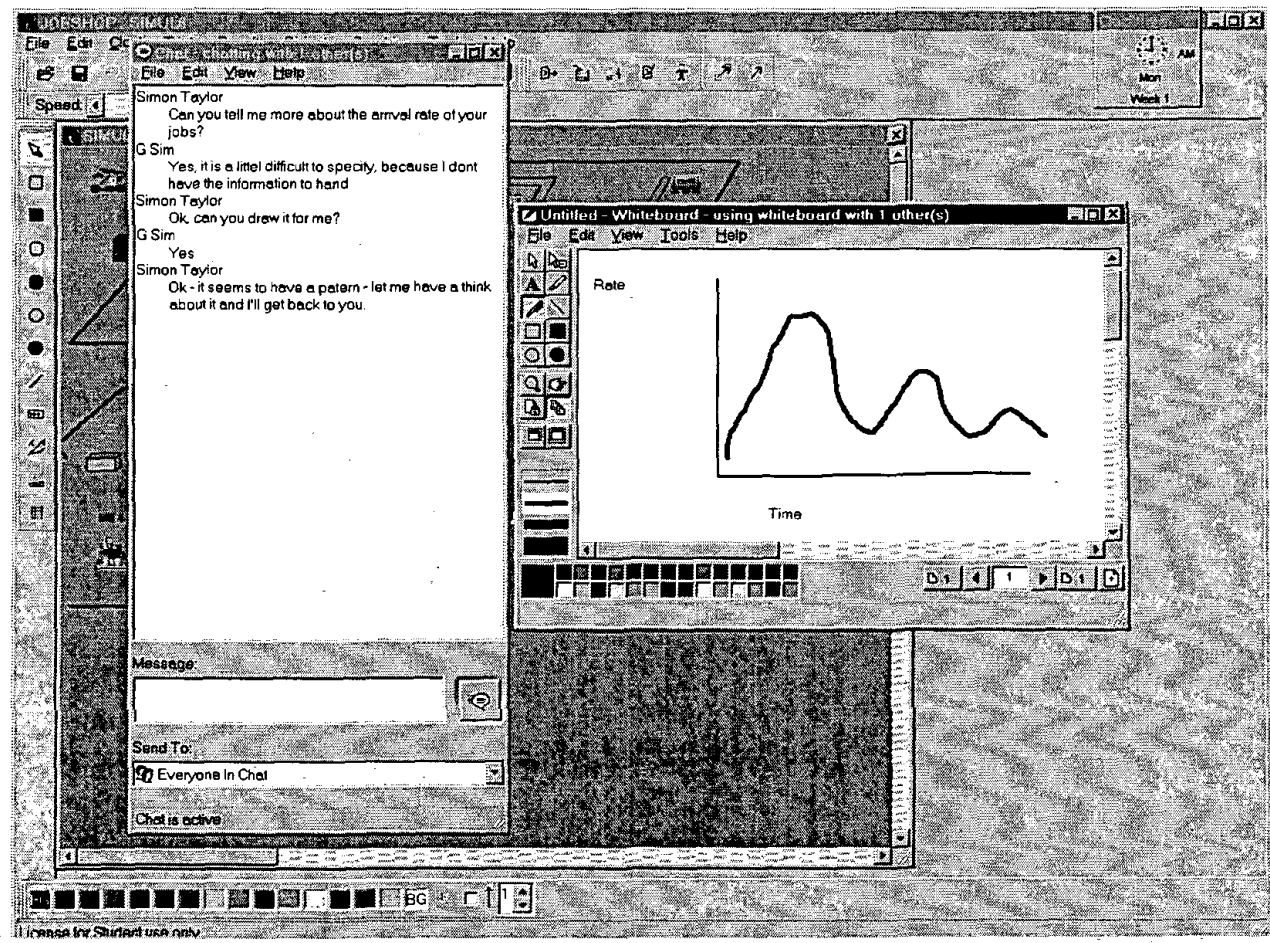

Figure 4: Text Chat and Whiteboard

To end this paper on a positive note, this work has already had at least one success story. NetMeeting was demonstrated to a representative a major automotive company in April 2000. This led to NetMeeting successfully linking a simulation modelling application across three sites (two in London, one in the USA). Since then at least one company that provides this company with modelling software has introduced NetMeeting for end user support. This, and the fact that NetMeeting is now being used regularly in the company, demonstrates that netconferencing and simulation modelling are a sensible combination. It is hoped that this paper and its associated activities in the simulation modelling community, will contribute to the transfer of academic research into practical cost savings and better working practices in industry.

\section{ACKNOWLEDGMENTS}

The work in this paper has been supported by the GROUPSIM research programme (EPSRC grant GR/N35304).

\section{REFERENCES}

Baecker, R. 1993. Readings in groupware and computer supported cooperative work. Morgan Kauffmann, San Mateo, CA.
Dataquest. 1999. Can collaborative software double its revenue? <gartnerli.gartnerweb. com>. Accessed $22^{\text {nd }}$ July 1999.

Ellis, C.A., S.J. Gibbs, and G.L. Rein. 1991. Groupware: Some issues and experiences. Communications of the $A C M, 34(1): 39-58$.

Field, A. 1996. Group Think. Inc. Technology Magazine. 3:38+. <www.inc.com/incmagazine/ archives/ 17960381. html>. Accessed 17 July 2000 .

Grief, I. 1988. Computer supported cooperative work: a book of readings. Morgan Kauffmann, San Mateo, CA.

Grudin, J. 1994. Computer Supported Cooperative Work: History and Focus. IEEE Computer, 2(5):19-26.

Grudin, J and L. Palen. 1995. Why groupware succeeds: discretion or mandate? In Proceedings of ECSCW'95, 263-278. Kluwer.

Grudin, J and S.E. Poltrock. 1997. Computer-supported cooperative work and groupware. Advances in Computers. 45:269-320.

Johansen, R. 1988. Groupware: Computer support for business teams. The Free Press, New York, NY.

Johansen, R. 1991. Leading business teams, AddisonWesley, Reading, MA.

Law A.M. and W.D. Kelton. 1999. Simulation modelling and analysis. ( $3^{\text {rd }}$ ed). McGraw-Hill, New York, N.Y. 
Macredie, R, R. Paul, B. Lehaney, D. Anketell, and S. Warwick. 1999. Modelling for added value. SpringerVerlag, London.

News.com. 1999. Microsoft gains edge in groupware market. <www. news.com/News/Item/0,4, $37452,00 . \mathrm{html}>$. Accessed $22^{\text {nd }}$ July 1999.

Orfali, R., D. Harkey, and J. Edwards. 1996. The essential client/server survival guide second edition. Wiley Computer Publishing, John Wiley \& Sons, Inc. Chichester.

Pidd, M. 1998. Computer simulation in management science. $\left(4^{\text {th }} \mathrm{ed}\right)$. John Wiley \& Sons, Chichester.

Poltrock, S. and J. Grudin. 1998. CSCW, groupware and workflow: experiences, state of art, and future trends. In Proceedings of CHI'98. 119-120. ACM Press.

Robinson, S. 1994. Successful simulation: a practical approach to simulation projects. McGraw-Hill, Maidenhead, England.

Robinson, S. and M. Pidd. 1998. Provider and customer expectations of successful simulation projects. Journal of the Operational Research Society. 49(3):200-209.

Sproull, L and S. Kiesler. 1991. Connections: New ways of working in the networked organization. The MIT Press. Cambridge, MA.

Whitaker, R. (1996). Computer supported cooperative work (CSCW) and groupware: overview, definitions, and distinctions. <www. informatik. umu.se/ $\sim$ rwhit/CSCW. htm $1>$. Accessed $17^{\text {th }}$ July 2000.

\section{AUTHOR BIOGRAPHY}

SIMON J. E. TAYLOR <simon.taylor@brunel. ac. $u k>$ is the Chair of the Simulation Study Group of the UK Operational Research Society. He is a senior lecturer in the Department of Information Systems and Computing and is a member of the Centre for Applied Simulation Modelling, both at Brunel University, UK. He was previously part of the Centre for Parallel Computing at the University of Westminster. $\mathrm{He}$ has an undergraduate degree in Industrial Studies (Sheffield Hallam), a M.Sc. in Computing Studies (Sheffield Hallam) and a Ph.D. in Parallel and Distributed Simulation (Leeds Metropolitan). His main research interests are using distributed systems technology to improve simulation. This has led to the development of the GROUPSIM research programme which is dedicated to the transfer of relevant expertise from the CSCW and groupware, and distributed simulation communities into commercial simulation. He is also an active member of the Purple Theatre Company. 